\title{
Sistema de prospecção de competências emergentes: uma proposta de modelo
}

\author{
Jair Cunha Cardoso Filho \\ Doutorando; Universidade de Brasilia (UnB), Brasília, DF, Brasil; \\ jaircardosofilho@uol.com.br \\ Rogério Henrique de Araújo Júnior \\ Doutor; Universidade de Brasilia (UnB), Brasília, DF, Brasil; \\ rogerio.araujo.jr@gmail.com
}

\begin{abstract}
Resumo: A questão do emprego e desenvolvimento de competências emergentes apresentam-se como temas relevantes para a sociedade da informação e do conhecimento em uma economia globalizada e competitiva. Aborda-se o problema do apagão de mão de obra e as estratégias governamentais brasileiras e de organismos multilaterais de competências emergentes para mitigá-lo. Propõe-se, então, um modelo sistêmico de monitoramento ambiental para prospecção de competências emergentes, amparado nos paradigmas social e técnico-econômico da Ciência da Informação e baseado no monitoramento ambiental e na competência informacional. Portanto, além do conceito de competências emergentes, são abordados também os conceitos de competência informacional e monitoramento ambiental. Conclui-se, por fim, que tal modelo contribui para associar as ações de qualificação profissional aos esforços de desenvolvimento regional e de inclusão social, e que tanto o monitoramento ambiental de ambientes de negócio quanto a identificação de competências emergentes podem auxiliar na construção de estratégias organizacionais de longo prazo para o desenvolvimento do capital humano.
\end{abstract}

Palavras-chave: Competências emergentes. Monitoramento ambiental. Competência informacional.

\section{Introdução}

$\mathrm{Na}$ atual sociedade da informação e do conhecimento em economia global, o mercado de trabalho brasileiro exige, em todos os seus níveis, profissionais capacitados para responder às necessidades desenvolvimentistas do Estado e das organizações empresariais. No entanto, o mercado de recursos humanos, dadas 
as mudanças ocorridas no mundo do trabalho, não corresponde a essa expectativa na mesma intensidade.

Novos perfis de trabalho e elevados padrões de qualificação profissional são exigidos pelas empresas, que por sua vez precisam ser suficientemente ágeis para adaptarem-se às exigências dos clientes e dos mercados. Comentando sobre a nova ordem social advinda da sociedade da informação e do conhecimento, Tarapanoff (2001, p. 55) assevera que:

[...] a competitividade dos setores produtivos e dos países passa a depender mais da educação e do preparo de seus trabalhadores e povo, e de sua capacidade de gerar e utilizar conhecimento e inovação.

Nessa direção, estudos de futuro e cenários prospectivos apontam a qualificação profissional como um dos principais fatores condicionantes para a empregabilidade dos trabalhadores, para o incremento da produtividade e da competitividade das empresas e, por conseguinte, para a competitividade dos países dentro de uma economia globalizada que se baseia na informação e no conhecimento.

O tradicional modelo taylorista/fordista de qualificação profissional já não é mais suficiente, e vem sendo substituído pelo modelo da competência, mais apropriado ao toyotismo e aos novos paradigmas sociotécnicos aderentes aos desafios do mundo globalizado. Nessa direção, Zarifian (2003, p. 37-38) afirma que:

[...] a competência é uma nova forma de qualificação ainda emergente. É uma maneira de qualificar [...] Portanto, não se deve fazer nenhuma distinção conceitual entre competência e qualificação, a não ser para dizer que o modelo da competência especifica, hoje, de maneira nova, a construção da qualificação [...] Essa qualificação é essencial tanto para posicionar o assalariado na organização do trabalho diante das condições de produção que o mobilizarão, como para determinar os níveis de salário.

A gradativa substituição do modelo de qualificação profissional fordista pelo modelo de competências faz com que as políticas públicas para a inserção de indivíduos no mercado de trabalho os preparem de forma antecipada para as 
demandas futuras, e conforme Zarifian (2003), para que se retirem da lógica do posto de trabalho. Além disso, servem também para fazer com que, de algum modo, o trabalho seja reapropriado pelo indivíduo que o realiza, como expressão direta da competência possuída e utilizada.

Como os objetivos destas políticas só poderão ser atingidos em longo prazo, por se tratarem de mudanças que levam gerações até serem consolidadas, deve-se buscar antecipar, da forma mais aproximada possível, os desafios, as necessidades e as possibilidades que a realidade social e econômica apresentará nos próximos anos. Surge daí a necessidade de mapeamento e investimento em competências emergentes.

Segundo Pompermayer et al. (2011), a escassez de competências e habilidades básicas na força de trabalho disponível provoca um aumento nos custos de produção, principalmente por transferir para as firmas parcelas cada vez maiores da formação de seus potenciais colaboradores. Esses autores sugerem que, visando o longo prazo, investimentos contínuos na educação, tanto básica quanto profissional e superior, devem ser considerados como soluções para que tais cenários de escassez não sejam prolongados. É válido lembrar que tal investimento se refletirá em força de trabalho mais qualificada somente em um horizonte de tempo mais distante, reforçando a necessidade de se pensar em políticas públicas apropriadas para os contextos e cenários específicos, nos quais algum grau de escassez se evidencie (POMPERMAYER et al., 2011).

A esse respeito, o Boletim Eletrônico da Agência Brasileira de Desenvolvimento Industrial (ABDI), publicado em junho de 2013, afirma que:

Os empresários, por exemplo, não apresentam informações muito consolidadas e confiáveis de demanda por qualificação e formação e a falta desta clareza dificulta o processo de aproximar a oferta das reais necessidades da sociedade [...]. (BOLETIM..., 2013, p. 9).

Torna-se necessário, então, coletar, tratar e divulgar da melhor forma informações sobre a demanda de competências emergentes, de modo a desenvolvê-las antecipadamente para responder às necessidades do mercado de trabalho em constante evolução, pois: 
As competências se transformaram na moeda global do século 21. Sem investimento adequado em competências, as pessoas permanecem às margens da sociedade, o progresso tecnológico não se traduz em crescimento econômico e os países não podem competir em uma sociedade mundial que se baseia cada vez mais no conhecimento. Mas essa "moeda" perde valor à medida que evoluem as exigências dos mercados de trabalho e as pessoas perdem as competências que não utilizam. As competências não se traduzem automaticamente em empregos. (ORGANIZAÇÃO PARA A COOPERAÇÃO E DESENVOLVIMENTO ECONÔMICO, 2014, p. 3).

Dada a importância da informação nesse contexto, se faz relevante a concertação entre organizações privadas, governos locais e sociedade civil organizada para que processos de qualificação ou de formação de competências sejam antecipadamente realizados, de forma que se possa acompanhar a evolução das exigências dos mercados de trabalho.

Nessa direção, este artigo é pautado na visão da Ciência da Informação (CI) voltada para os fins (WERSIG; NEVELING, 1975), na qual a CI é definida a partir do ponto de vista de que existem determinadas necessidades sociais a serem preenchidas e que ela deve servir a essas necessidades. Segue, ainda, a trilha aberta por Saracevic (1996) e Barreto (2002), quando afirmam que a Ciência da Informação, de campo inter e multidisciplinar e com responsabilidade social, ressalta os papeis econômico e social das atividades de informação em direção ao desenvolvimento nacional e ao progresso social (SARACEVIC, 1996) e promove o desenvolvimento e o progresso do indivíduo, de seu grupo e da sociedade por meio da informação como mediadora do conhecimento (BARRETO, 2002).

Nessa linha de pensamento, e considerando o papel social da Ciência da Informação, propõe-se um modelo sistêmico de prospecção de competências emergentes, de modo que processos de qualificação ou de formação de competências sejam antecipadamente realizados, com a finalidade de desenvolver nas pessoas, de forma proativa, os requisitos de conhecimentos e habilidades exigidos em mercados de trabalho ainda em construção.

Para tanto, a proposta metodológica que possibilitou o estudo foi o uso da técnica de grupo nominal proposta por Pinheiro, Farias e Abe-Lima (2013), e 
estudo de caso da Cidade Aeroportuária do Distrito Federal. A pesquisa foi de caráter qualitativo e, quanto aos fins, exploratória, descritiva e aplicada. Quanto aos meios, foi bibliográfica, documental e de levantamento. Os especialistas consultados validaram o modelo, e com o estudo de caso validou-se sua aplicação e replicação em situações similares.

\section{0 paradigma social da Ciência da Informação}

Conforme Capurro (2003), o paradigma social da Ciência da Informação integra o usuário como sujeito ativo do processo informacional, dotando-o de capacidade de objetivar suas necessidades de conhecimento e formular esquemas de busca, produção, transmissão, distribuição e consumo da informação, e sua aplicação em situações sociais concretas, contextualizadas. Aplica-se, portanto, ao contexto atual da sociedade da informação e do conhecimento, com seus novos problemas sociais, econômicos, técnicos, culturais e políticos, que devem ser enfrentados teórica e pragmaticamente pela Ciência da Informação como mediadora do conhecimento, sobretudo no que diz respeito à competência informacional que, conforme Miranda (2011, p. 249), é definida como:

[...] um conjunto de competências profissionais e organizacionais ligadas ao perfil de um profissional da informação ou de um profissional ligado a uma atividade baseada em informação, e pode ser expressa pela expertise em lidar com ciclos e contextos informacionais, aplicando-se tecnologias da informação. O ciclo da informação compreende todas as atividades relacionadas à coleta, ao tratamento e à divulgação de informações. Os contextos informacionais são aqueles que diferenciam e direcionam as atividades do ciclo da informação para determinadas formas de agregação de valor, como contexto da informação científica ou da informação para negócios. (MIRANDA, 2011, p. 249).

À vista disso, a competência informacional vai ao encontro do paradigma social da CI quando oferece aos sujeitos (organizações e indivíduos), a possibilidade de participar ativamente do ciclo informacional no contexto de mapeamento de competências emergentes, como ilustrado a seguir na Figura 1. 
Figura 1 - O paradigma social da CI no contexto das competências emergentes

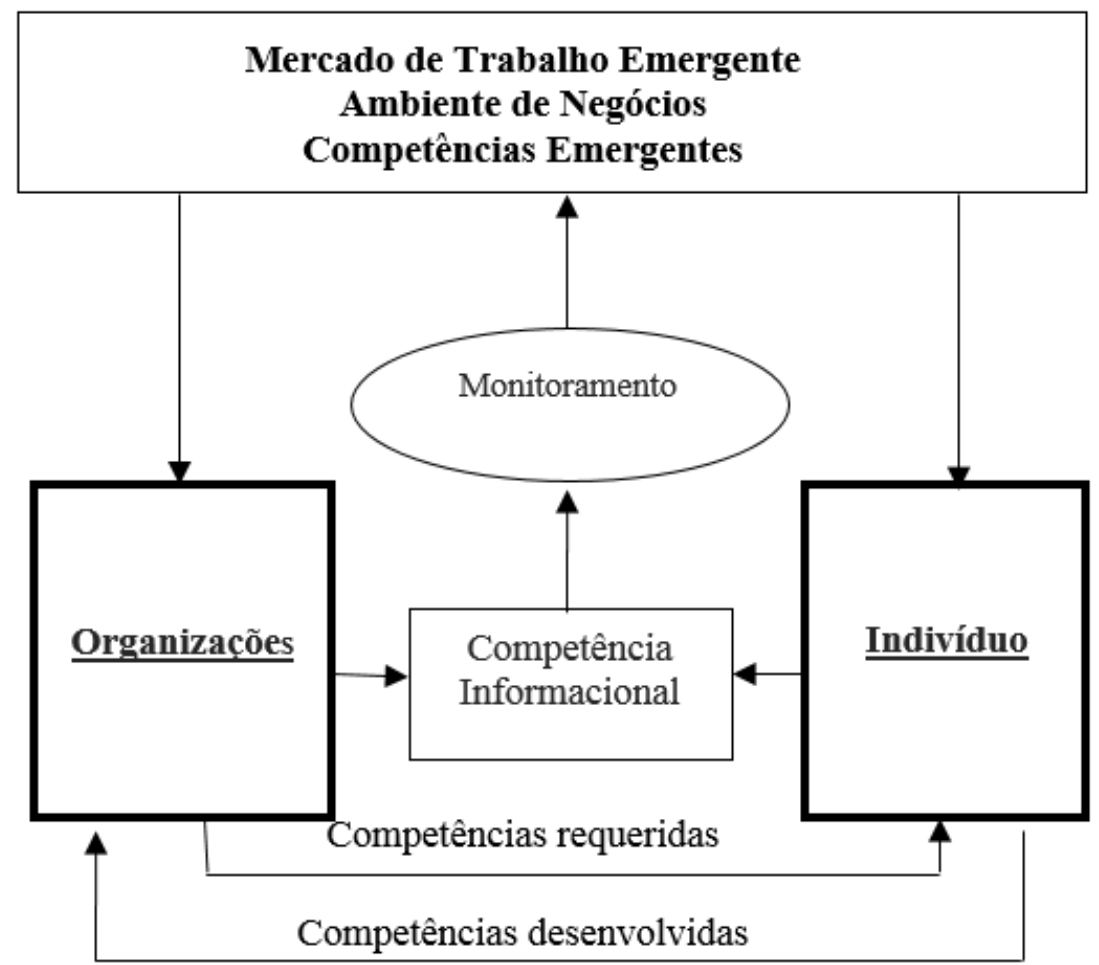

Fonte: dos autores

Por intermédio da competência informacional, tanto o indivíduo como as organizações realizam o monitoramento a partir da formulação de esquemas de busca, produção, tratamento, transmissão, distribuição e consumo da informação relativa à demanda e oferta de competências emergentes no ambiente de negócios e no mercado de trabalho, e de informação relativa à busca/oferta de capacitação/qualificação necessárias para o desenvolvimento dessas competências. Uma vez prospectada, essa informação torna o usuário (organizações/indivíduo) um sujeito ativo dentro do processo informacional, dotando-o de capacidade de objetivar suas necessidades de conhecimento/competências para aplicação em situações concretas, contextualizadas, conforme o paradigma social defendido por Capurro (2003). 


\section{0 paradigma técnico-econômico da Ciência da Informação}

Por outro lado, conforme Werthein (2000), o paradigma técnico-econômico, se refere às transformações técnicas, organizacionais e administrativas que têm como fator-chave a informação propiciada pelos avanços tecnológicos, os quais oferecem avanços significativos para a vida individual e coletiva, aumentam o nível dos conhecimentos gerados e utilizados na sociedade, e estimulam a aprendizagem constante e a mudança. Crawford (1994) já comentava sobre o paradigma técnico-econômico ao descrever sucintamente um modelo de como evoluem as economias e as sociedades: novos conhecimentos levam a novas tecnologias, que por sua vez levam a mudanças econômicas, as quais consequentemente geram mudanças sociais e políticas, que em última instância, criam um novo paradigma ou uma nova visão de mundo.

Em função disso, conforme Carvalho (2003), a qualificação dos trabalhadores tem sido considerada um fator fundamental e estratégico, sem a qual não se pode fazer frente aos desafios postos por esse paradigma. Esses desafios incluem a frequente adoção de novas tecnologias, a gestão eficaz da força de trabalho, o aproveitamento de diferentes fontes de mão de obra e o apoio à economia local, uma vez que à medida que o ambiente de negócios se altera, novos e diferentes conjuntos de competências emergem, exigindo novas qualificações profissionais. Trata-se de um ciclo permanente de inovação, monitoramento de competências emergentes e qualificação profissional.

Nesse caminhar, em tese as organizações sabem quais conhecimentos precisam desenvolver em seus empregados para aumento de sua produtividade e competitividade no ambiente de negócios. Entretanto, resta saber se o indivíduo possui as informações necessárias para decidir que tipo de qualificação ou competências devem ser buscadas por ele para que seu próprio capital intelectual the possibilite maiores rendimentos salariais e oportunidades de trabalho e de emprego no mercado de trabalho emergente.

E sobre esse assunto, Arruda (1997) sinaliza que a possibilidade de inserção do indivíduo no mercado de trabalho vai depender de sua capacidade de realizar as escolhas certas para seu aprimoramento e/ou de sua família, sendo 
necessário que, para ter chances de se realizar, a escolha seja articulada com a demanda do mercado de trabalho.

\section{A abordagem da proposta}

Este artigo apresenta uma abordagem interdisciplinar diferenciada na Ciência da Informação, que acompanha a tendência internacional de antever necessidades de formação de competências com vistas ao crescimento econômico e social de regiões e territórios.

A Figura 2, a seguir, representa a abordagem de prospecção de competências emergentes proposta, focada no monitoramento proativo do ambiente de negócios, para perscrutar sinais que apontem para a necessidade de competências emergentes alinhadas a mercado de trabalho futuro, com vistas ao desenvolvimento socioeconômico de indivíduos, regiões e territórios.

Figura 2 - Abordagem de prospecção de competências emergentes

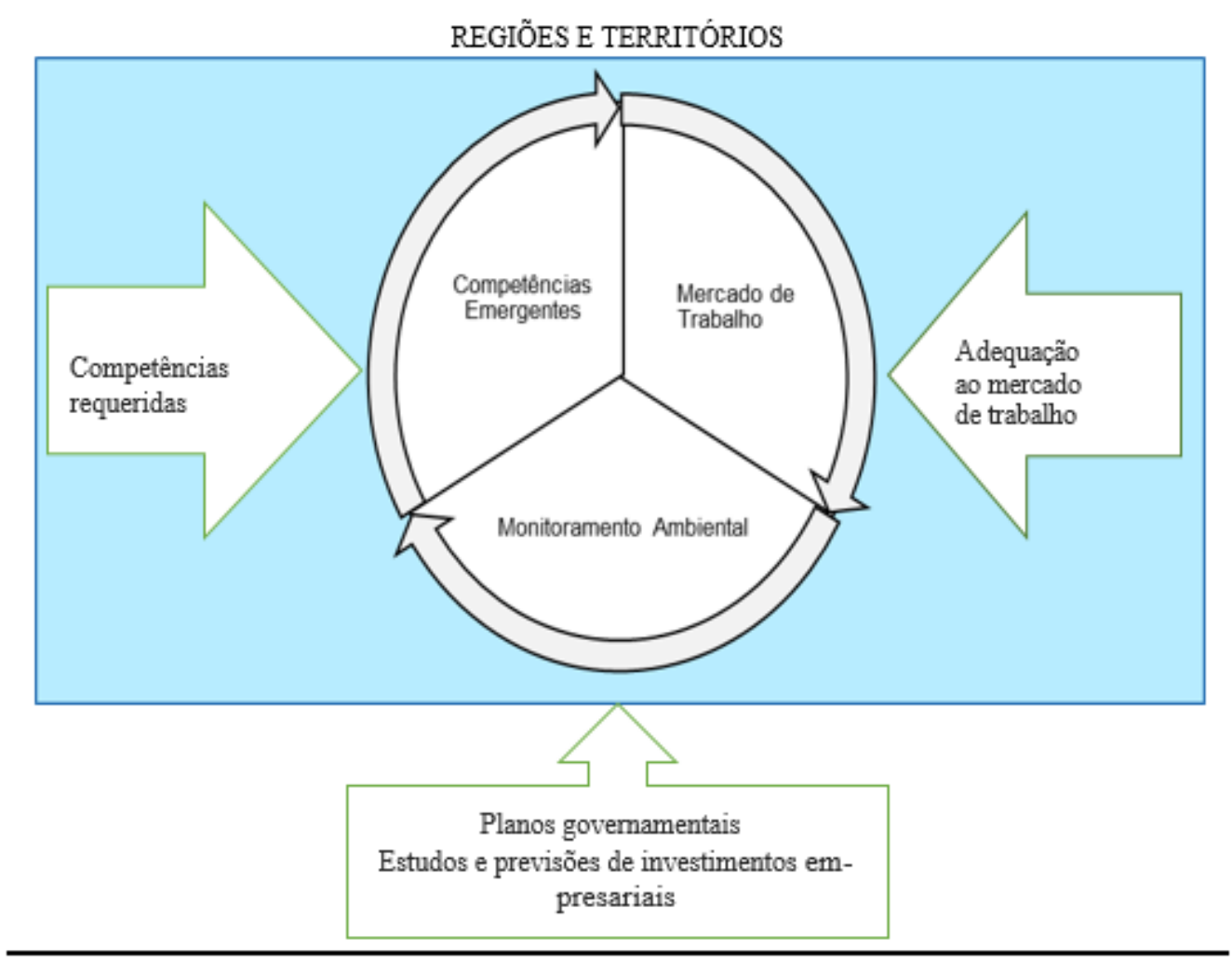

Fonte: dos autores. 
A abordagem acima representada não trata de realizar estudos de futuro e de prospectiva, tal como preconizado por Schwartz (1993) ou por Godet e Durance (2007) no que se refere à elaboração de cenários, mas de apropriar-se deles e implementar ações, de modo que parcelas cada vez mais amplas da população possam participar e beneficiar-se do processo de crescimento econômico de sua região ou território.

A abordagem propõe o monitoramento de planos governamentais de desenvolvimento econômico e social (nacional, regional, territorial ou local), de estudos e previsões de investimentos empresariais e estatais, e das competências a serem requeridas para inserção de indivíduos em mercados de trabalho emergentes ou em expansão aderentes àqueles planos, estudos e previsões dentro deste ambiente.

Daí o porquê da prospecção de competências emergentes: para a adequação de indivíduos a mercados de trabalho também emergentes, de forma a possibilitar o desenvolvimento antecipado de competências individuais com vistas à multiplicação de oportunidades para os habitantes das regiões nas quais os empreendimentos se instalarão, evitando assim o chamado "apagão de mão de obra”. Concomitantemente, o monitoramento ambiental, ao permitir o acompanhamento e a análise de informações do ambiente externo, oferece a possibilidade de antecipação de soluções de problemas e tomada de decisão estratégica em relação à emergência de competências futuras a serem disponibilizadas no mercado de trabalho.

Nessa direção, entendendo que a sociedade e os setores empresariais vêm pressionando o Estado por políticas públicas duradouras que sustentem o crescimento e o desenvolvimento econômico e social e, ao mesmo tempo, exigindo transparência e ações globalizantes, a premissa considerada neste artigo é a de que um modelo de monitoramento ambiental para prospecção de competências emergentes de fato contribui para associar as ações de qualificação profissional a esforços de desenvolvimento local e de inclusão social. 


\section{Sobre competência informacional}

Devido ao seu caráter interdisciplinar, a Ciência da Informação discute o tema da competência alinhada ao desenvolvimento organizacional e à gestão de pessoas sob o enfoque da informação, dos processos de agregação de valor à informação, de sistemas de informação, estudos de usuários da informação, e de unidades de informação. Sob esse enfoque, uma tipologia de competência, denominada competência informacional (information literacy ou letramento informacional) vem à tela.

Bruce (2002) destaca que a idéia de letramento informacional (ou competência informacional) surgiu no início dos anos 1970. Com o advento das tecnologias de informação cresceu, tomou forma e fortaleceu-se para se tornar reconhecida como competência crítica e abrangente para o século XXI, “[...]fundamental para alcançar tanto a capacitação pessoal quanto o desenvolvimento econômico. (BRUCE, 2002, p. 1). Entretanto, de acordo com Vitorino e Piantola (2009, p. 131-132),

[...] desde seu surgimento, o uso do termo information literacy tem sido alvo de intensas discussões, já que historicamente se entende literacy apenas em um nível básico de aquisição de habilidades, mais especificamente, de leitura e de escrita. [...]. Em língua portuguesa, a tradução do termo também gera controvérsias, tendo sido empregadas na literatura existente expressões como competência em informação, competência informacional, letramento informacional [...].

Virkus (2003) afirma que na sociedade da informação, as habilidades necessárias para encontrar, avaliar e usar efetivamente a informação tornaram-se maiores, mais complexas e mais importantes, enquanto Conceição (2011) diz que para que possa se inserir nesse cenário, o indivíduo deve desenvolver habilidades específicas para manusear adequadamente a informação, principalmente no que tange à produção de conhecimento, localização, acesso, uso e comunicação.

Miranda (2011) lembra que na sociedade da informação, informação e conhecimento são riquezas que criam riquezas, de modo que competências ligadas ao saber, ao saber-fazer e ao saber-agir relacionadas à informação e ao co- 
nhecimento são essenciais para que os profissionais assegurem sua empregabilidade e as organizações, por sua vez, assegurem sua sobrevivência.

Concordando com Miranda (2011), Ribeiro (2012) afirma que seja com foco nas tecnologias da informação ou na apreensão da informação, existe um consenso quanto à importância de se adquirir competências para atuar em ambientes informacionais. Esta visão é compartilhada com Vitorino e Piantola (2009), que asseveram que o uso consciente, criativo e benéfico da informação se tornou essencial para a atuação do indivíduo no contexto social contemporâneo, em uma relação de aprendizado ao longo da vida.

Ainda nesse contexto, Vitorino e Piantola (2009), oferecendo um panorama internacional, histórico e conceitual das pesquisas sobre a competência informacional, apontam que a partir do ano 2000, os pesquisadores

[...] estão desenvolvendo uma consciência coletiva em relação ao espaço de estudos construído em torno da competência informacional, o que nos parecem sinais promissores que fazem emergir o papel social da competência informacional como um caminho essencial na construção e manutenção de uma sociedade livre, verdadeiramente democrática, em que os indivíduos fariam escolhas mais conscientes e seriam capazes de determinar o curso de suas vidas. (VITORINO; PIANTOLA, 2009, p. 138).

Belluzzo, Kobayashi e Feres (2004) afirmam que a competência em informação deve ser compreendida como um fator relevante dentro do contexto social contemporâneo e que, além disso,

[...] é importante que as pessoas possam conhecer como o conhecimento está organizado, como buscar a informação, como utilizá-la de modo inteligente e como proceder ao processo de comunicação do conhecimento gerado. [...] Assim, da mesma forma que os profissionais da informação, os cidadãos precisam aprender a acessar e usar a informação de forma inteligente. [...]. Convém lembrar que a competência em informação apresenta diferentes concepções que podem ser resumidas no que segue: [...] Social concepção com ênfase na inclusão social, consistindo em uma visão integrada de aprendizagem ao longo da vida e o exercício da cidadania [...] (BELUZZO; FERES, 2015, p. 15-17).

Reforçando o papel social da competência informacional, a Declaração de Alexandria sobre competência informacional e aprendizado ao longo da 
vida, documento elaborado em colóquio realizado na Biblioteca de Alexandria, no Egito, no período de 6 a 9 de novembro de 2005, proclama que:

A competência informacional e o aprendizado ao longo da vida são os faróis da Sociedade da Informação, iluminando os caminhos para o desenvolvimento, a prosperidade e a liberdade.

A competência informacional está no cerne do aprendizado ao longo da vida. Ele capacita as pessoas em todos os caminhos da vida para buscar, avaliar, usar e criar a informação de forma efetiva para atingir suas metas pessoais, sociais, ocupacionais e educacionais. É um direito humano básico em um mundo digital e promove a inclusão social em todas as nações.

$\mathrm{O}$ aprendizado de toda a vida prepara os indivíduos, as comunidades e as nações a atingir suas metas e a aproveitar as oportunidades que surgem no ambiente global em evolução para um benefício compartilhado. Auxilia-os e suas instituições a enfrentar os desafios tecnológicos, econômicos e sociais, para reverter a desvantagem e incrementar o bem-estar de todos. (THE ALEXANDRIA PROCLAMATION..., 2006).

Nesse contexto, e pelo alinhamento do conceito ao tema deste artigo, ao paradigma social da Ciência da Informação apresentado por Capurro (2003), e à responsabilidade social da Ciência da Informação (SARACEVIC, 1996; BARRETO, 2002), adota-se que Competência Informacional, tal como na Declaração de Alexandria:

a) abrange as competências para reconhecer as necessidades informacionais e localizar, avaliar, aplicar e criar informação dentro de contextos culturais e sociais;

b) é crucial para a vantagem competitiva dos indivíduos, empresas (especialmente as pequenas e médias), regiões e nações;

c) fornece a chave para o acesso, uso e criação efetivos do conteúdo para dar apoio ao desenvolvimento econômico, à educação, à saúde e aos serviços, e a todos os outros aspectos das sociedades contemporâneas [...]; e

d) vai além das tecnologias atuais para abranger o aprendizado, o pensamento crítico e as habilidades interpretativas cruzando as fronteiras profissionais, além de capacitar indivíduos e comunidades. (THE ALEXANDRIA PROCLAMATION..., 2006).

Desse modo, a Figura 3 apresenta um modelo no qual competências individuais, organizacionais e informacionais são articuladas num processo que avança do micro ao macrocosmo, alcançando indivíduos, organizações e comunidades, mundo organizacional e mundo do trabalho. 
Figura 3 - Representação das tipologias de competências

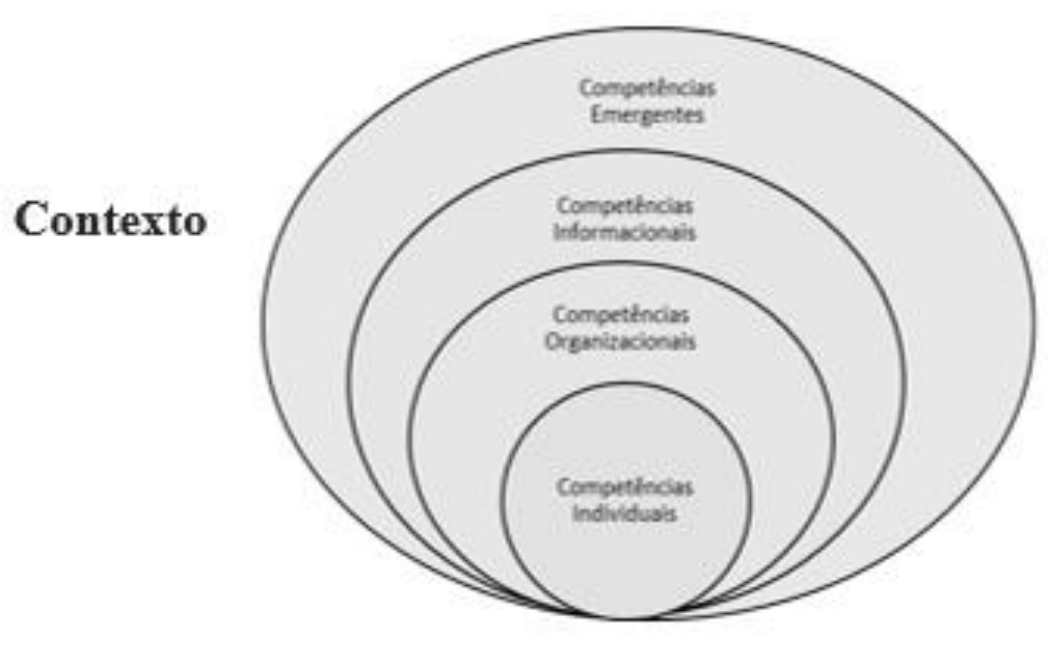

Fonte: dos autores.

Coloca-se também que essas tipologias de competência são elementos que podem estar contidos em um conjunto maior, classificado como "Competências Emergentes".

\section{Sobre competências emergentes}

A tipologia denominada Competências Emergentes é trazida à cena por Sparrow e Bognanno (1994) e Nisembaum (2001). Ao considerarem a existência de uma relação entre a dinâmica do ambiente organizacional e a qualificação profissional, os autores acabam por afirmar que as competências se comportam em temos temporais de acordo com as inovações tecnológicas e mudanças estratégicas corporativas, e classificam competências de acordo com sua relevância e importância em um determinado contexto ao longo do tempo. As competências são então classificadas como estáveis, transicionais (ou transitórias), declinantes e emergentes.

Para esses autores, as competências estáveis são aquelas que permanecerão sendo tão importantes no futuro quanto são importantes no presente. Representam o cerne dos processos de negócio e permanecem relevantes ao longo do tempo, e devem ser mantidas para assegurar a continuidade da organização. As 
competências transicionais ou transitórias são aquelas competências que, embora essenciais em alguns momentos, não estão diretamente relacionadas ao negócio, não são diretamente relevantes para o trabalho e nem enfatizadas na estratégia da organização, mas, no entanto, são fundamentais para a gestão de processos de mudança. Declinantes são aquelas competências que tiveram grande importância na vida organizacional em um passado recente, mas que estão se tornando cada vez menos relevantes devido a mudanças nas estratégias de organização, na tecnologia ou na natureza do trabalho. Por fim, emergentes são aquelas competências que apesar de não serem relevantes em determinada organização no momento presente, serão enfatizadas no futuro a partir da estratégia definida pela empresa. A abordagem do ciclo de vida adotada por Sparrow e Bognanno (1994) permite à organização e seus colaboradores a adoção de atitudes proativas desenvolvendo no presente competências que terão relevância no futuro.

Nisembaum (2001), de forma semelhante ao tratar de aspectos relacionados ao desempenho diferenciado de indivíduos no contexto organizacional, classifica as competências de acordo com seu status e relevância na organização, designando-as como maduras, emergentes e de transição, da seguinte forma: madura, é a que já faz parte do capital intelectual da organização; considera-se de transição a que pode ter importância para um determinado momento da organização, e emergente, aquela que terá relevância num futuro próximo. Ambos os autores caminham na mesma direção ao classificarem competências emergentes de forma semelhante: aquelas que terão relevância num futuro próximo (NISEMBAUM, 2001) e aquelas que, apesar de não serem relevantes em um dado momento presente, serão enfatizadas no futuro (SPARROW; BOGNANNO, 1994).

McLagan (1997), na mesma linha, atenta às práticas de treinamento e desenvolvimento de recursos humanos nas organizações, também aborda a tipologia de competências emergentes quando sugere criar hipóteses sobre o futuro do trabalho e do seu ambiente. E então, a partir disso, orientar indivíduos e equipes para pensar nas implicações das mudanças nas estratégias empresariais e no ambiente de trabalho, e em quais competências deverão ser requeridas e salientadas 
com base naquelas premissas futuristas. McLagan (1997) alega ainda que para sobreviver, as organizações precisam aprender a cuidar de sua "base de competência humana" e proporcionar autonomia sobre tarefa, técnica, equipe e tempo para manter sua competência essencial alinhada às necessidades e ao ritmo acelerado da sociedade. A autora, então, traz um modelo conceitual, visualizado na Figura 4, que representa um sistema de competência que liga pessoas, trabalho e estratégia, acreditando que a autonomia possibilita ao indivíduo liberdade de escolha sobre que conhecimentos, habilidades ou conjuntos de atributos devem ser desenvolvidos e alavancados em quatro áreas importantes em um ambiente de trabalho: a tarefa desenvolvida, a técnica utilizada, a participação em equipes e o tempo de duração de suas competências em uma sociedade de mudanças aceleradas.

Figura 4 - Modelo conceitual de McLagan

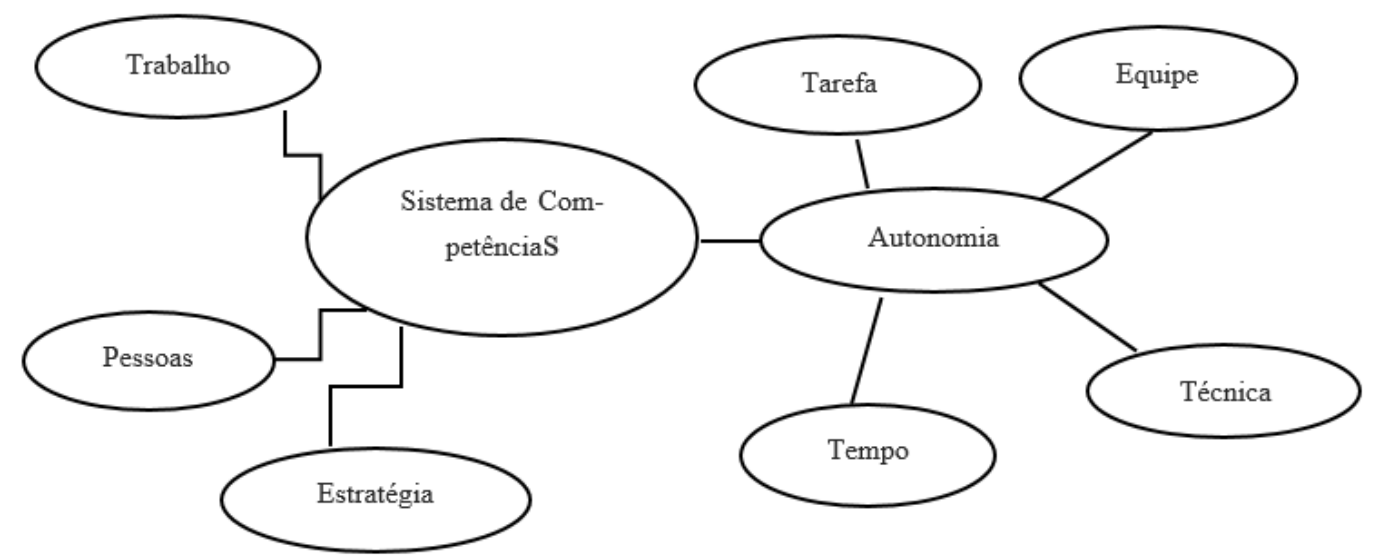

Fonte: McLagan (1997).

Com efeito, Majumdar (2004) sugere algumas competências que entende como sendo genéricas e essenciais para a sobrevivência do trabalhador na competitiva economia do conhecimento:

a) competências de utilização da informação: os trabalhadores do conhecimento precisam desenvolver a capacidade de obter, localizar, pesquisar e encontrar informações para a efetiva tomada de decisão. É 
preciso que saibam avaliar informações e saber como usar e também se comunicar com elas;

b) autonomia para desenvolvimento de competências: rápidas mudanças tecnológicas exigem a capacidade de diagnosticar e prescrever suas próprias necessidades de formação, de gerenciar suas próprias carreiras e de desenvolver continuamente novas competências ao longo da vida.

A abordagem de competências emergentes aponta então para uma condição incerta, para a qual é necessária uma ação proativa de monitoramento ambiental e prospecção de cenários para que se vislumbre a distância do futuro (próximo ou distante), as variáveis e determinantes que o envolvem e para que se antecipem as demandas de qualificação profissional que serão relevantes e importantes em dados contextos ao longo do tempo.

\section{Sobre o monitoramento ambiental}

Certo e Peter (1993) entendem que as variáveis ambientais devem ser constantemente examinadas pela empresa e definem "análise do ambiente" como o ato de monitorar o ambiente organizacional para identificar riscos e oportunidades presentes ou futuros que possam influenciar o atingir das metas de uma organização. Kotler (1998) compartilha dessa mesma visão, e afirma que uma unidade de negócios precisa monitorar as forças macroambientais (demográficas, econômicas, tecnológicas, políticas, sociais, legais e culturais) para estabelecer um sistema de inteligência para acompanhar mudanças importantes. Moresi (2001) ressalta o papel do processo de monitoramento ambiental como fornecedor de informação para tomada de decisão estratégica e, fundamentado no ciclo da informação, como adicionador de novas capacidades organizacionais para atuação no ambiente, dentro de uma realidade percebida. Para Moresi, Prado e Alcântara (2010, p. 3), o monitoramento ambiental:

[...] pode ser conceituado como um processo de coleta de dados e informações sobre o ambiente externo, que serão processados pela organização, visando auxiliar os gerentes a identificar 
oportunidades, detectar e interpretar problemas, planejar futuras ações e implementar adaptações estratégicas ou estruturais em suas organizações. Trata-se de uma área do conhecimento que se alimenta de diversas disciplinas, tais como o planejamento, o processo decisório, o estudo de usuários de informação, além de outras. [...]. É um processo de filtragem de uma grande quantidade de informação para atender alguma necessidade, segundo critérios específicos.

Sob o ponto de vista da identificação de oportunidades, detecção e interpretação de problemas, planejamento de ações futuras e implementação de estratégias, o monitoramento ambiental pode também ser considerado sob a ótica da Prospectiva Estratégica, idealizada por Godet e Durance (2007), que a considera como uma reflexão que visa iluminar a ação organizacional, em particular aquela que possui um caráter estratégico.

A Prospectiva Estratégica, segundo Godet e Durance (2007, p.12) procura responder às seguintes indagações que uma organização faz a si mesma: “o que pode acontecer?", “o que posso fazer?”, “o que vou fazer?” e "como vou fazê-lo?". Destacam ainda que o processo de antecipação de mudanças no ambiente, de contextualização das ameaças e oportunidades do ambiente externo e apropriação das necessidades de adaptações estratégicas ou estruturais internas, e de efetiva mobilização das capacidades de realização (resposta àquelas indagações) é conduzido pelos próprios atores sociais, os stakeholders, envolvidos no processo decisório.

Ainda nesse campo, Mintzberg, Ahlstrand e Lampel (2010), ao discutirem modelos de gestão estratégica, abordam a Escola do Design. Segundo os autores, essa escola enfatiza que para a tomada de decisão a respeito da estrutura organizacional e das estratégias de enfrentamento de mudanças, é necessário avaliar as ameaças e oportunidades do ambiente externo, considerando o contexto social, político e macroeconômico. Abordam ainda a Escola Cognitiva como um processo mental que constrói ou interpreta o ambiente no qual a organização está inserida, a partir de informações ricas e ambíguas, complexas e contraditórias que precisam ser interpretadas para que façam sentido. Ao mesmo tempo, a Escola do Aprendizado, também citada por aqueles autores, afirma que as reali- 
dades políticas requerem um processo de aprendizagem coletiva, tal como no entendimento de Certo e Peter (1993).

Blanck e Janissek-Muniz (2014) entendem monitoramento do ambiente como a observação de um conjunto de fatores, tanto externos quanto internos, que podem comprometer ou influenciar positivamente a atuação de uma organização. Nesse contexto do monitoramento, Janissek-Muniz, Lesca e Freitas (2006) trazem o conceito de sinais fracos:

informações antecipativas (sinais de alerta precoces) de um ambiente socioeconômico externo à empresa, passíveis de ser captadas em elementos de informação dispersos e de ocorrência variada, aos quais normalmente não se presta a devida atenção mas que, combinados com outros de mesmo tipo ou não, podem induzir a certas ideias e inferir ações a realizar, podendo, inclusive, reduzir assimetrias da informação. (JANISSEK-MUNIZ; LESCA; FREITAS, 2006, p. 97).

A abordagem dos sinais fracos reforça a ideia de que, para reduzir a assimetria de informação, é necessária a ancoragem da informação a um contexto que faça sentido para que possa ser monitorado adequadamente, sobretudo no que se refere à contextualização de fatos que incorporem a prospecção de competências emergentes às demandas de qualificação profissional, que serão relevantes e importantes em dadas situações ao longo do tempo.

\section{Competências emergentes: estratégias de competências da OCDE}

A Organização para a Cooperação e Desenvolvimento Econômico (OCDE), é uma organização internacional composta por 34 países e com sede em Paris, na França. Seu objetivo é promover políticas que visem o desenvolvimento econômico e o bem-estar social de pessoas por todo o mundo. A estratégia de competências proposta pela OCDE (2014) assevera que é preciso desenhar políticas de competências para que esses investimentos tragam maiores benefícios sociais e econômicos. Se propõe o desenvolvimento de competências adequadas para responder às necessidades do mercado de trabalho, com suporte aos governos para coletar e utilizar melhor a informação sobre a demanda de competências em 
constante mutação, cobrindo não só os desafios imediatos, mas também com visão de longo prazo, de forma a transformar melhores competências em melhores trabalhos, crescimento econômico e inclusão social.

\section{Estratégias de competências da OIT}

A Organização Internacional do Trabalho (OIT), preocupada com a crise mundial de desemprego juvenil, aponta a educação e a qualificação como fatores essenciais para que os jovens possam se incorporar ao mercado de trabalho com êxito, uma vez que incrementam sua produtividade e empregabilidade potencial (ORGANIZAÇÃO INTERNACIONAL DO TRABALHO, 2013).

Para mitigar esse fenômeno o estudo propõe, para os países membros, dentre outras estratégias:

[...] o desenvolvimento de políticas e programas que tenham por objetivo neutralizar o descompasso de habilidades técnicas entre os jovens, tais como programas de formação profissional, recapacitação de jovens desempregados e planos de qualificação profissional no local de trabalho, e ii) a necessidade de maior informação sobre o mercado de trabalho e sistemas de análise, para servir de base para o monitoramento dos mercados de trabalho e desenhar e implementar políticas públicas efetivas. (ORGANIZAÇÃO INTERNACIONAL DO TRABALHO, 2013).

A OIT (2013) sugere ainda que os sistemas de desenvolvimento de competências também devem ajudar os trabalhadores e as empresas a se adaptarem às atuais e futuras mudanças econômicas, tecnológicas e sociais. Recomenda, então, outras estratégias: políticas de formação e de desenvolvimento de competências, adequação da formação às exigências do mercado de trabalho, antecipação de necessidades de competências, e desenvolvimento de competências para a inclusão social, criando capacidade de resposta às necessidades do indivíduo, da sociedade e da economia. 


\section{Estratégias de competências da União Europeia (UE)}

O Conselho da União Europeia (2010) entende que a educação e a formação são cruciais para o progresso econômico e social, e que alinhar as competências às necessidades do mercado de trabalho desempenha um papel fundamental neste processo. Nesse contexto, os países membros da UE, visando promover o crescimento inteligente, sustentável e inclusivo do continente, produziram um documento chamado Estratégia Europa 2020, que no domínio da educação e da formação profissional, estabelece quatro objetivos estratégicos:

i) tornar a aprendizagem ao longo da vida e a mobilidade uma realidade, ii) melhorar a qualidade e a eficácia da educação e da formação, iii) promover a igualdade, a coesão social e a cidadania ativa, e iv) incentivar a criatividade, a inovação e o empreendedorismo a todos os níveis de ensino e formação (CONSELHO DA UNIÃO EUROPEIA, 2010).

Baseada nesse documento, a Comissão Europeia para Emprego, Assuntos Sociais e Inclusão (2014), pautada nas recomendações da OCDE e da OIT, estabeleceu estratégias, como melhorar as competências profissionais, promover uma melhor antecipação das necessidades futuras em matéria de competências, antecipar-se às necessidades do futuro mercado de trabalho, contribuir para uma melhor adequação entre competências e necessidades do mercado de trabalho, preencher a lacuna entre o mundo da educação e o mundo do trabalho e adequar a oferta e a procura neste domínio.

\section{Estratégias de competências do Brasil}

A estratégia brasileira de competências está embutida em três programas federais voltados para o ensino técnico profissionalizante e de estímulo às engenharias: o Programa Nacional de Acesso ao Ensino Técnico e Emprego (Pronatec), Instituído pela Lei $\mathrm{n}^{\circ}$ 12.513, de 26 de outubro de 2011 (BRASIL, 2011); o Plano Nacional Pró-Engenharia, que tem por objetivo principal aumentar, tanto em quantidade quanto em qualidade os concluintes da graduação em engenharia nas Instituições de Ensino Superior (IES) públicas e 
privadas, e o Programa Ciência sem Fronteiras, instituído pelo Decreto no 7.642, de 13 de dezembro de 2011.

Diferentemente do preconizado pela OCDE e pela OIT de melhor utilizar a informação sobre a demanda de competências com visão de longo prazo, percebe-se que na estratégia brasileira parece não haver ampla divulgação para que os cidadãos (trabalhadores e estudantes) definam com autonomia sua trilha de qualificação profissional e aprendizagem ao longo da vida, de modo que se encaminhem na direção das competências e mercados de trabalho emergentes. Registra-se, então, a assimetria de informação entre demanda e oferta de competências emergentes.

\section{Conclusão}

A importância da informação no contexto de necessária concertação entre entes políticos e sociais apoia a visão da Ciência da Informação voltada para os fins (WERSIG; NEVELING, 1975), na qual a CI é definida a partir do ponto de vista de que existem determinadas necessidades sociais a serem preenchidas e que a $\mathrm{CI}$ deve servir a essas necessidades.

Um modelo de monitoramento ambiental para prospecção de competências emergentes contribuiria para associar as ações de qualificação profissional a esforços de desenvolvimento regional e local, e de inclusão social. Do mesmo modo, o monitoramento ambiental de ambientes de negócios e a identificação de competências emergentes podem ser processos úteis para auxiliar a construção de estratégias organizacionais de longo prazo para o desenvolvimento do capital humano.

No campo da Ciência da Informação, constatou-se uma lacuna epistemológica de estudos sobre o tema de Competências Emergentes, alinhado ao tema de Monitoramento Ambiental. Por meio da revisão da literatura, da técnica grupo nominal e do estudo de caso, a lacuna foi preenchida, dando margem a propostas de estudos futuros e de aperfeiçoamentos. 
O presente artigo teve como objetivo maior a proposição de um modelo sistêmico de prospecção de competências emergentes, amparado nos paradigmas social e técnico-econômico da Ciência da Informação e tendo como base o monitoramento ambiental e a competência informacional.

Verificou-se, por fim, que o modelo aqui sugerido, validado por especialistas e testado em estudo de caso específico, poderá contribuir para a prospecção de competências emergentes, reduzindo o grau da assimetria de informações entre demanda e oferta de competências emergentes, e aumentando o grau de atualização, pelas organizações formadoras de mão de obra, da oferta de cursos técnicos e tecnológicos ao mercado de trabalho em conformidade com a demanda por competências emergentes.

O processo denominado Monitoramento Ambiental, aliado à capacidade de lidar com o ciclo informacional (competência informacional) mostraram ser bons fundamentos para a sustentação dos pilares do sistema: os paradigmas social e técnico-econômico, a visão voltada para os fins e a responsabilidade social da Ciência da Informação.

\section{Referências}

ARRUDA, Gerardo Clesio Maia. Qualificação profissional nos tempos presentes: decifra-me ou te devoro. In: CARLEIAL, Liana; VALLE, Rogério (Org.). Reestruturação produtiva e mercado de trabalho no Brasil. São Paulo: HUCITEC-ABET, 1997.

BARRETO, Aldo de Albuquerque. A condição da informação. São Paulo em Perspectiva, São Paulo, v. 16, n. 3, 2002.

BELLUZZO, Regina Célia Baptista; FERES, Glória Georges. Competência em informação, redes de conhecimento e as metas educativas para 2021: reflexões e inter-relações. In: BELUZZO, Regina Célia Baptista; FERES, Glória Georges; VALENTIM, Marta Lígia Pomim (Org.). Redes de conhecimento e competência em informação: interfaces da gestão, mediação e uso da informação/organização. Rio de Janeiro: Interciência, 2015.

BELLUZZO, Regina Célia Baptista; KOBAYASHI, Maria do Carmo Monteiro; FERES, Glória Georges. Information literacy: um indicador de competência 
para a formação competente de professores na sociedade do conhecimento. Educação Temática Digital, Campinas, v. 6, n. 1, p. 81-99, dez. 2004.

BLANCK, Mery; JANISSEK-MUNIZ, Raquel. Inteligência estratégica antecipativa coletiva e crowdfunding: aplicação do método L.E.Scanning em empresa social de economia peer-to-peer (P2P). Revista de Administração, São Paulo, v. 49, n. 1, p.188-204, jan./ mar. 2014.

BOLETIM ELETRÔNICO da Rede de Pesquisa Formação e Mercado de Trabalho. Brasília: ABDI, n. 2, jun. 2013. Disponível em:

$<$ http://www.brasilmaior.gov.br/images/data/201306/632765779ac7578d17bc09 c39569cf7e.pdf>. Acesso em: 31 maio 2016.

BRASIL. Lei $n^{\circ} 12.513$, de 26 de outubro de 2011. Institui o Programa Nacional de Acesso ao Ensino Técnico e Emprego (Pronatec); altera as Leis no 7.998, de 11 de janeiro de 1990, que regula o Programa do Seguro-Desemprego, o Abono Salarial e institui o Fundo de Amparo ao Trabalhador (FAT), no 8.212 , de 24 de julho de 1991, que dispõe sobre a organização da Seguridade Social e institui Plano de Custeio, $\mathrm{n}^{\mathrm{o}}$ 10.260, de 12 de julho de 2001, que dispõe sobre o Fundo de Financiamento ao Estudante do Ensino Superior, e n ${ }^{\circ} 11.129$, de 30 de junho de 2005, que institui o Programa Nacional de Inclusão de Jovens (ProJovem); e dá outras providências. Diário Oficial [da] União, Brasília, DF, 27 out. 2011. Seção 1, p. 1.

BRUCE, Christine. Information literacy as a catalyst for educational change: a background paper. In: INFORMATION LITERACY MEETING OF EXPERTS, 2002, Prague. [Proceedings...]. Prague, UNESCO, 2002.

CAPURRO, Rafael. Epistemologia e ciência da informação. In: ENCONTRO NACIONAL DE PESQUISA EM CIÊNCIA DA INFORMAÇÃO, 5, 2003, Belo Horizonte. Anais. Belo Horizonte: ENANCIB, 2003. Disponível em: <http://www.capurro.de/enancib_p.htm>. Acesso em: 28 abr. 2011.

CARVALHO, Olgamir Francisco de. Educação e formação profissional: trabalho e tempo livre. Brasília: Plano, 2003.

CERTO, Samuel C.; PETER, J. Paul. Administração estratégica:

planejamento e implantação da estratégia. São Paulo: Makron Books, 1993.

COMISSÃO EUROPEIA PARA EMPREGO, ASSUNTOS SOCIAIS E INCLUSÃO. Novas competências para novos empregos. Bruxelas: Comissão Europeia, 2014. Disponível em:

<http://ec.europa.eu/social/main.jsp?catId=822\&langId=pt>. Acesso em: 31 maio 2016.

CONCEIÇÃO, Vilma Gravatá da. Competência em informação na perspectiva da educação continuada: um olhar sob a práxis do profissional da 
informação. 2011. Dissertação (Mestrado em Ciência da Informação) - Instituto de Ciência da Informação, Universidade Federal da Bahia, Salvador, 2011.

CONSELHO DA UNIÃO EUROPEIA. Cooperação da União Europeia no domínio da educação e da formação (EF 2020). 2010. Disponível em: <http://eur-lex.europa.eu/legal-content/PT/TXT/?uri=URISERV\%3Aef0016>. Acesso em: 24 fev. 2014.

CRAWFORD, Richard. Na era do capital humano: o talento, a inteligência e o conhecimento como forças econômicas, seu impacto nas empresas e nas decisões de investimento. São Paulo: Atlas, 1994.

GODET, Michel; DURANCE, Phillipe. Prospectiva estratégica: problemas y métodos. 2. ed. San Sebastián: PROSPEKTIKER, 2007. (Cuadernos de LIPSOR, $\mathrm{n}^{\mathrm{o}}$ 20).

JANISSEK-MUNIZ, Raquel; LESCA, Humbert; FREITAS, Henrique. Inteligência estratégica antecipativa e coletiva para tomada de decisão. Organizações em contexto, São Bernardo do Campo, ano 2, n. 4, p. 92-118, jul./dez. 2006.

KOTLER, Philip. Administração de marketing. 5. ed. São Paulo: Atlas, 1998.

MAJUMDAR, Shyamal. Emerging generic skills for employability in the knowledge economy. Denkendorf: Fest Didactic, 2004.

MCLAGAN, Patricia A. Competencies: the next generation. Training and development, Alexandria, v. 51, n. 5, p. 40-47, May 1997.

MINTZBERG, Henry; AHLSTRAND, Bruce; LAMPEL, Joseph. Safári de estratégia: um roteiro pela selva do planejamento estratégico. 2. ed. Porto Alegre: Bookman, 2010.

MIRANDA, Silvânia V. de. Aprendizagem organizacional e desenvolvimento de competências informacionais. In: TARAPANOFF, Kira (Org.). Aprendizado organizacional: contexto e propostas. Curitiba: Ibpex, 2011.

MORESI, Eduardo Amadeu Dutra. Inteligência organizacional: um referencial integrado. Ciência da Informação, Brasília, v. 30. n. 2, p. 35-46, maio/ago. 2001.

MORESI, Eduardo Amadeu Dutra; PRADO, Hércules Antônio do; ALCÂNTARA, Alexandre de. Cenários prospectivos, monitoração ambiental e metadados. DataGramaZero: Revista de Ciência da Informação, Rio de Janeiro, v. 11, n. 1, fev. 2010. 
NISEMBAUM, Hugo. Gestão do conhecimento. In: BOOG, Gustavo (Coord.) Manual de treinamento e desenvolvimento: um guia de operações. São Paulo: Makron Books, 2001.

\section{ORGANIZAÇÃO PARA A COOPERAÇÃO E DESENVOLVIMENTO} ECONÔMICO. Melhores competências, melhores empregos, melhores condições de vida: uma abordagem estratégica das políticas de competências. São Paulo: Fundação Santillana, 2014. Disponível em: <http://dx.doi.org/10.1787/9788563489197-pt>. Acesso em: 20 fev. 2014.

ORGANIZAÇÃO INTERNACIONAL DO TRABALHO. Centro Internacional de Formação da OIT. Academia sobre a formação e o desenvolvimento de Competências: desenvolvimento de competências para uma maior produtividade, geração de emprego e desenvolvimento. Turim, 2013. Disponível em:

<http://www.oit.org/public/portugue/region/eurpro/lisbon/pdf/ilo_skillsacademy 2013 flyerpt.pdf>. Acesso em: 25 fev. 2014.

PINHEIRO, José de Queiroz; FARIAS, Tadeu Mattos; ABE-LIMA, July Yukie. Painel de especialistas e estratégia multimétodos: reflexões, exemplos, perspectivas. Psico, Porto Alegre, v. 44, n. 2, p. 184-192, abr./jun. 2013.

POMPERMAYER, Fabiano Mezadre et al. Potenciais gargalos e prováveis caminhos de ajustes no mundo do trabalho no Brasil nos próximos anos. Radar: Tecnologia, Produção e Comércio Exterior, Brasília, DF, n. 12, p. 7-14, mar. 2011.

RIBEIRO, Ana Paula Santos. Usos da internet e competência informacional: um estudo com associadas da Abong em Salvador/BA. 2012. Dissertação (Mestrado em Ciência da Informação) - Instituto de Ciência da Informação, Universidade Federal da Bahia, Salvador, 2012.

SARACEVIC, Tefko. Ciência da informação: origem, evolução e relações. Perspectivas em Ciência da Informação, Belo Horizonte, v. 1, n. 1, p. 41-62, jan./jun. 1996.

SCHWARTZ, Peter. La planification stratégique par scenários. Futuribles, Paris, n. 176, mai 1993.

SPARROW, Paul R.; BOGNANNO, Mario. Competency requeriment forecasting: issues for internacional selection and assesment. In: MABEY, Christopher; ILES, Paul (Ed.). Managing learning. London: Routledge, 1994. cap. 5.

TARAPANOFF, Kira. O contexto da mudança. In: TARAPANOFF, Kira (Org.). Inteligência organizacional e competitiva. Brasília: UnB, 2001.

THE ALEXANDRIA PROCLAMATION on information literacy and 
lifelong learning. In: HIGH-LEVEL COLLOQUIUM ON INFORMATION LITERACY AND LIFELONG LEARNING, 2005, Alexandria. Report of a meeting. [S.1.]: IFLA, 2006.

VIRKUS, Sirje. Information literacy in Europe: a literature review. Information Research, Lund, v. 8, n. 4, 2003. Disponível em: <http://informationr.net/ir/84/paper159.html> Acesso em: 31 maio 2016.

VITORINO, Elizete Vieira; PIANTOLA, Daniela. Competência informacional: bases históricas e conceituais: construindo significados. Ciência da Informação, Brasília, DF, v. 38, n. 3, p.130-141, set./dez., 2009.

WERSIG, Gernot; NEVELING, Ulrich. The phenomena of interesting to information science. InformationScientist, London, v. 9, n. 4, p. 127-140, Dec. 1975.

WERTHEIN, Jorge. A sociedade da informação e seus desafios. Ciência da Informação, Brasília, v. 29, n. 2, p. 71-77, maio/ago. 2000. Disponível em: <http://revista.ibict.br/ciinf/index.php/ciinf/article/view/254/1705>. Acesso em: 13 set. 2013.

ZARIFIAN, Philippe. O modelo da competência: trajetória, desafios atuais e propostas. São Paulo: SENAC, 2003.

\title{
Prospecting system of emerging skills: a proposal of model
}

\begin{abstract}
Employment and development of emerging skills are becoming relevant issues for the Information and Knowledge society inside a globalized and competitive economy. The lack of skilled manpower and the Brazilian strategies and multi-lateral organizations of emerging skills are approached with an intention of fix-ing its problems. In this paper, a systemic model to prospect for emerging powers supported the social, technical and economic paradigms of information science and based on environmental monitoring and information literacy is proposed. It discusses the concept of emerging skills, information literacy and environmental monitoring. It concludes that an environmental monitoring model for prospect-ing emerging skills helps to associate the professional qualifications of shares to regional development efforts and social
\end{abstract}


inclusion, and environmental monitoring business environments and the identification of emerging skills can be useful processes to help build long-term organizational strategies for the development of human capital.

Keywords: Emerging Skills. Environmental Monitoring. Information Literacy.

Recebido: 18/10/2015

Aceito: 11/04/2016 